\title{
Systematic review and meta-analysis: gray-scale ultrasound and shear wave elastography in the diagnosis of primipara pregnancy and delivery
}

\author{
Yi Qu ${ }^{1}$, Huiyuan Sun ${ }^{2}$, Jingjing Chen ${ }^{1}$, Jingjing Bai ${ }^{1}$, Yajing Liu ${ }^{1}$, Yang You ${ }^{3}$ \\ ${ }^{1}$ Department of Nursing, Children's Hospital of Hebei Province, Shijiazhuang, China; ${ }^{2}$ Science and Education Department, Children's Hospital of \\ Hebei Province, Shijiazhuang, China; ${ }^{3}$ Department of Medical Imaging, Fourth Hospital of Hebei Medical University, Shijiazhuang, China \\ Contributions: (I) Conception and design: Y Qu, Y You; (II) Administrative support: H Sun; (III) Provision of study materials or patients: J Chen, J \\ Bai, Y Liu, Y You; (IV) Collection and assembly of data: All authors; (V) Data analysis and interpretation: Y Qu, J Chen, J Bai, Y Liu, Y You; (VI) \\ Manuscript writing: All authors; (VII) Final approval of manuscript: All authors. \\ Correspondence to: Yang You. Fourth Hospital of Hebei Medical University, 12 Jiankang Road, Shijiazhuang, China. Email: youyoung96@163.com.
}

Background The combination of shear wave elastography (SWE) and gray-scale ultrasound is widely used
in the measurement of female pelvic floor muscle. However, the value of gray-scale ultrasound combined
with SWE in the evaluation of primipara pregnancy and delivery is still controversial.

Methods: Using the PubMed, Web of Science, Spring and Science Direct databases, clinical studies on gray-scale ultrasound combined with SWE on the diagnosis of primiparous pregnancy and childbirth published from January 2010 to December 2020 were searched. The RevMan5.3 software was used to conduct a meta-analysis of the indicators of gray-scale ultrasound combined with SWE for primiparas and non-primiparas, including: age, body mass index (BMI), gestational age at examination, gestational age at delivery, fetal weight, cervical length, shear wave velocity (SWV), front lip SWV, back lip SWV, Young's modulus and SWE index. Heterogeneity of the assessment results was tested using Cochran's chi-square.

Results: A total of 13 articles were included. Age, BMI before delivery, gestational age (when gray-scale ultrasound was combined with SWE examination), gestational age at delivery, neonatal weight, cervical depth, SWV of placental margin, SWV of anterior lip, SWV of posterior lip and Young's modulus of the study group were significantly different from those of the control group. The elastic modulus of the perineal body and the SWE of the anterior lip of the study group were significantly higher than those of the control group [mean difference $(\mathrm{MD})=8.11,4.39,95 \%$ confidence interval $(\mathrm{CI}): 3.90-12.31,0.94-7.83 ; Z=3.78,2.49$, $\mathrm{P}=0.0002,0.01]$. The SWE of the posterior lip in the study group was significantly lower than that in the control group ( $\mathrm{MD}=-4.34,95 \% \mathrm{CI}:-7.23$ to $1.44 ; \mathrm{Z}=2.93, \mathrm{P}=0.003)$.

Discussion: The number of cases in the control group in the included articles was significantly more than that in the observation group, and there were fewer descriptions of gray-scale ultrasound combined with SWE indicators in the included articles. There may be a certain degree of bias for indicators without obvious heterogeneity, and further analysis was required through a large number of clinical verifications. However, this study can provide certain reference values for the diagnosis of primipara pregnancy.

Keywords: Gray-scale ultrasound; shear wave elastography (SWE); pregnancy; meta-analysis

Submitted Sep 07, 2021. Accepted for publication Nov 12, 2021.

doi: 10.21037/apm-21-2672

View this article at: https://dx.doi.org/10.21037/apm-21-2672 


\section{Introduction}

The female pelvic floor is mainly composed of fascia, ligaments, nerves, and blood vessels. The anus muscle group plays an important role in pelvic floor support (1). The clinical manifestations of female pelvic floor dysfunction are pelvic organ prolapse, stress urinary incontinence, and fecal incontinence, which seriously affect the quality of life of women (2). There is a significant correlation between pelvic floor dysfunction and anal levator injury. Related studies have found that pregnancy and childbirth are one of the main causes of anal levator injury (3). Vaginal electromyography, magnetic resonance imaging (MRI), Oxford muscle strength grading, and ultrasound are commonly used to evaluate pelvic floor muscle contraction (4). The results of vaginal electromyography are easily affected by motor coordination and instruction responsiveness (5). Oxford muscle strength grading is subjective and has poor repeatability (6). MRI has better tissue contrast, but it is susceptible to metal contraceptive devices (7). Ultrasound can clearly observe the anatomical morphology and contractile function of the puborectalis muscle of the subject, but it cannot reveal the three-dimensional morphology and surrounding structure of the anal levator muscle (8). Two-dimensional grayscale ultrasound images can display the size, shape, and internal echo of tissue $(9,10)$. Nyhus et al. pointed out that the sonography of the perineal body can be observed using cavity gray-scale ultrasound, and the perineal body strength can be reflected by measuring the perineal body shape before and after the contraction. However, the measured value is easily affected by subjective factors and image quality. In addition, although gray-scale ultrasound can directly display the shape and damage of the levator ani muscle, it can't quantify the elasticity of the levator ani muscle. Ultrasound elastography uses ultrasound imaging methods, which can indirectly reflect the mechanical differences such as the elastic modulus inside the tissue $(11,12)$. Shear wave elastography (SWE) is an emerging ultrasound imaging technique that can quantitatively evaluate soft tissue elasticity. SWE generates a shear wave of sufficient intensity by emitting acoustic radiation pulses to stimulate the tissue. Through high-speed imaging and color-coding technology, it can real-time display the tissue elasticity map, quantitatively obtain the value of tissue Young's modulus, quantitatively evaluate tissue elasticity, and can measure the absolute value of tissue elastic modulus and quantitatively evaluate tissue hardness (13). SWE has been widely used in the diagnosis of diseases such as liver, thyroid, breast, and fetal growth and development due to its non-invasive, simple operation, and high reproducibility $(14,15)$. However, SWE results are easily affected by factors such as calcification in the lesion, large blood vessels, respiratory movement, measurement depth, and the nature of the tissue around the lesion (16).

In recent years, the new ultrasound-elastography technology has become a research hotspot in the imaging field. It makes up for the shortcomings of ordinary ultrasound, can quantitatively display information such as the hardness and morphology of the tissue, and can reduce the impact of a single SWE operation (17). Erdoğan et al. [2020] researchers used gray-scale ultrasound combined with SWE to measure the Young's modulus of the puborectal muscle in the resting and contracted state of the lithotomy position of infertile and fertile women; and the results show that the combination of first-order ultrasound and SWE to evaluate the perineal elastic modulus of healthy women without childbearing has a certain degree of feasibility and stability (18). Studies have applied SWE to the measurement of pelvic floor muscles, and found that SWE has certain value in the evaluation of female pelvic floor organ prolapse, muscle contraction and elastic characteristics, and pelvic floor levator ani muscle elasticity (19). Some researchers pointed out that the results of SWE combined with gray-scale ultrasound showed that the morphological changes of the bladder neck of primiparas with postpartum stress urinary incontinence were not obvious, but the bladder neck elasticity was lower than that of primiparas with no postpartum stress urinary incontinence (20). The results of Gachon et al. [2019] showed that SWE ultrasound elastography showed that the average Young's modulus of the perineum of the primipara was reduced, and the Young's modulus of the perineum of the primipara was significantly different with different delivery methods (21). These studies confirm that there is still some controversy regarding the value of SWE in the evaluation of primipara pregnancy and childbirth.

To summarize, there is still some controversy about the value of gray-scale ultrasound combined with SWE in the evaluation of primipara gestation. Therefore, this article describes a meta-analysis on gray-scale ultrasound combined with SWE for primipara pregnancy delivery at home and abroad and discusses the value of SWE in evaluating the delivery of primiparas to provide a reference value for the diagnosis of pelvic dysfunction in primiparas.

We present the following article in accordance with the PRISMA reporting checklist (available at https://dx.doi. 
org/10.21037/apm-21-2672).

\section{Methods}

\section{Methods of inclusion}

Primiparas who underwent ultrasound examination in obstetrics and gynecology departments were selected as the research objects. The types of included studies were retrospective control studies and prospective cohort studies. The control group included healthy women who had no children and those with reproductive histories as a multipara. Data included author/s, year, country, number of subjects, age of subjects, and observation indicators.

\section{Inclusion and exclusion criteria}

\section{Inclusion criteria}

Clinical trial Science Citation Index (SCI) and Engineering Index (EI) articles published from January 2010 to December 2020, which report original data; reported on the analysis of gray-scale ultrasound combined with SWE in the diagnosis of primiparas' pregnancy and delivery; and basic data on patients' age, gender, and group membership were recorded in detail. Moreover, body mass index (BMI), gestational age at delivery, gestational age at delivery, fetal weight, cervical length, shear wave velocity (SWV) in the central part of placenta, changes of SWV of placenta margin, SWV of anterior lip, SWV of posterior lip, Young's modulus, and shear wave elasticity of anterior lip and posterior lip of the control group and the study group were recorded and counted in detail.

\section{Exclusion criteria}

The followings were excluded: duplicate publications, literature reviews, non-English publications, publications that do not obtain original data, single case reports, animal experiment reports, and publications without index data.

\section{Literature retrieval strategy}

Online databases were searched including PubMed (2010-2012/2020), Nature (2010-2012/2020), Web of Science (2010-2012/2020), Spring (2010-2012/2020) and Science Direct (2010-2012/2020) using the keywords "shear wave elastography (SWE)", "gray-scale ultrasound", "primiparas", "pregnancy", "delivery" and "diagnosis". The keywords "OR" and "AND" were used for joint searches.
Searches were performed to identify clinical studies of grayscale ultrasound combined with SWE in the diagnosis of primiparas during pregnancy. After retrieving all key words and performing multiple searches, the search engines were used to identify the publications meeting the search criteria. In particular, studies reporting gray-scale ultrasound combined with SWE for the diagnosis of primipara pregnancy delivery were searched and assessed.

\section{Literature screening and data extraction}

The selection of relevant literature and the extraction of research indicators were extracted independently by two investigators, and a third investigator was consulted in case of discrepancies. The Cochrane evaluation manual 4.2.6 was used to conduct the evaluation of the included records. The evaluation criteria included: (I) whether the research methods were correct and clear; (II) whether the research results were clear and definite; and (III) whether an intention-to-treat analysis method was used to analyze the results. According to the Cochrane Reviewer' Handbook, the literature was divided into three categories (low risk, unclear risk, and high risk). Through reading titles, records were screened, and authors were contacted to supplement data reported if necessary to assist with screening. Next, abstracts and full texts were read to determine whether the record should be included. For each selected study, information on all available variables was extracted and entered into a Microsoft Excel database. The following details were extracted: (I) basic information: article title, first author, publication year, publication journal, type of study, commencement and completion of research; (II) subjects: number of subjects included in the study, age of the subjects, and BMI and gestational age at the time of examination and delivery; (III) evaluation methods: statistics and analysis of the main indicators of the study group and the control group; (IV) observation indicators: BMI, gestational age at delivery, fetal weight, cervical length, SWV, SWV of anterior lip, SWV of posterior lip, Young's modulus, and SWE of anterior lip and posterior lip.

\section{Statistical analysis}

All data were analyzed using STATA 12 software (Stata Corporation, College Station, TX, USA). To assess heterogeneity of the results, the Cochran chi square test was used to evaluate the test level $\alpha=0.1$, and $\mathrm{I}^{2}$ was used to quantitatively analyze the heterogeneity. According 
to the results of the heterogeneity test, the appropriate combination method was selected. If $\mathrm{P}>0.1$ or $\mathrm{I}^{2} \leq 50 \%$, this indicated that the heterogeneity of the included studies was small, and the fixed effect model (FEM) was used for merging. If $\mathrm{P} \leq 0.1, \mathrm{I}^{2}>50 \%$, this meant that the heterogeneity of the included studies was large, and thus it was necessary to further analyze the sources of heterogeneity and eliminate the heterogeneity as far as possible. After excluding the effects of heterogeneity, a meta-analysis was conducted using the random effects model (REM). The mean differences (MDs) and standard deviations (SDs) were used to measure the data, and the estimated values and $95 \%$ confidence intervals (CIs) of each effect were generated. If necessary, MDs and SDs were calculated based on the median and CI or range available. A sensitivity analysis was conducted by excluding the lowest quality score, the test level was $\alpha=0.05$.

\section{Results}

\section{Literature screening process and retrieval results}

After searching the PubMed, Web of Science, Spring, Nature and Science Direct databases using keywords such as "SWE", "gray-scale ultrasound", "primiparas", "pregnancy", "delivery" and "diagnosis", 233 English articles published from January 2010 to December 2020 were initially identified. Among them, 144 articles were retrieved through PubMed, 39 articles through Web of Science, 15 articles through Spring, 8 articles through Nature, 18 articles through Science Direct, and nine articles were identified through references searches of identified articles. Endnote X8 software was used to screen for duplicate references, and 72 articles were obtained. Based on titles, article abstracts and contents of articles, literature reviews, reports of meetings, case reports, and risk factor assessments were excluded. After preliminary screening, 22 articles were retrieved, which initially met the inclusion criteria. After reading the full texts of these articles, nine articles that did not include the original data and a control study was excluded. Finally, 13 articles were analyzed (21-34), and the literature screening process is shown in Figure 1. The specific details of the literature retrieval are shown in Table 1. The results of bias risk assessment of the included records are shown in Figures 2,3. All studies obtained 7 to 10 scores using the Newcastle-Ottawa scale (NOS) bias risk assessment (range, 0 to 10), and all of these were high-quality articles.

\section{Age}

All except one of the 14 articles reported the mean ages of each group (Figure 4). Statistical analysis showed that there was significant age heterogeneity between the control group and the study group $\left(\mathrm{I}^{2}=74 \%, \mathrm{P}<0.0001\right)$, and therefore a random effect model was used for analysis. The results showed that there was no significant statistical difference in the mean ages of the two groups ( $M D=0.06,95 \% \mathrm{CI}:-0.21$ to $0.32 ; \mathrm{Z}=0.43, \mathrm{P}=0.67$ ).

\section{Comparison of fetal age with grayscale ultrasound and SWE}

According to the statistical analysis of the gestational age of gray-scale ultrasound combined with SWE in the five included articles (Figure 5), the gestational age of the two groups at the time of examination showed significant heterogeneity $\left(\mathrm{I}^{2}=81 \%, \mathrm{P}<0.00003\right)$, and the random effect model analysis showed that there was no significant difference in the gestational ages of the two groups at the time of examination ( $\mathrm{MD}=0.36,95 \% \mathrm{CI}:-1.37$ to 2.10 ; $\mathrm{Z}=0.41, \mathrm{P}=0.68)$.

\section{BMI comparison}

According to the statistical analysis of maternal BMI before delivery in the six included articles (Figure 6), there was significant heterogeneity between the control group and the study group $\left(\mathrm{I}^{2}=67 \%, \mathrm{P}=0.009\right)$, and the random effect model analysis showed that there was no significant heterogeneity between the two groups ( $M D=-0.69,95 \%$ CI: -1.54 to $0.16 ; \mathrm{Z}=1.58, \mathrm{P}=0.11$ ).

\section{Comparison of fetal age at delivery}

According to the statistical analysis of the gestational age of the pregnant women at delivery in the six included articles (Figure 7), the gestational age of the two groups at delivery showed significant heterogeneity $\left(\mathrm{I}^{2}=94 \%, \mathrm{P}<0.00001\right)$. The random effect model analysis showed that there was no significant difference in the gestational age of the two groups at the time of examination ( $\mathrm{MD}=-0.95,95 \% \mathrm{CI}$ : -2.22 to $0.33 ; \mathrm{Z}=1.46, \mathrm{P}=0.14$ ).

\section{Neonatal weight}

According to the statistical analysis of neonatal weight in the 


\section{Identification of studies via databases and registers}
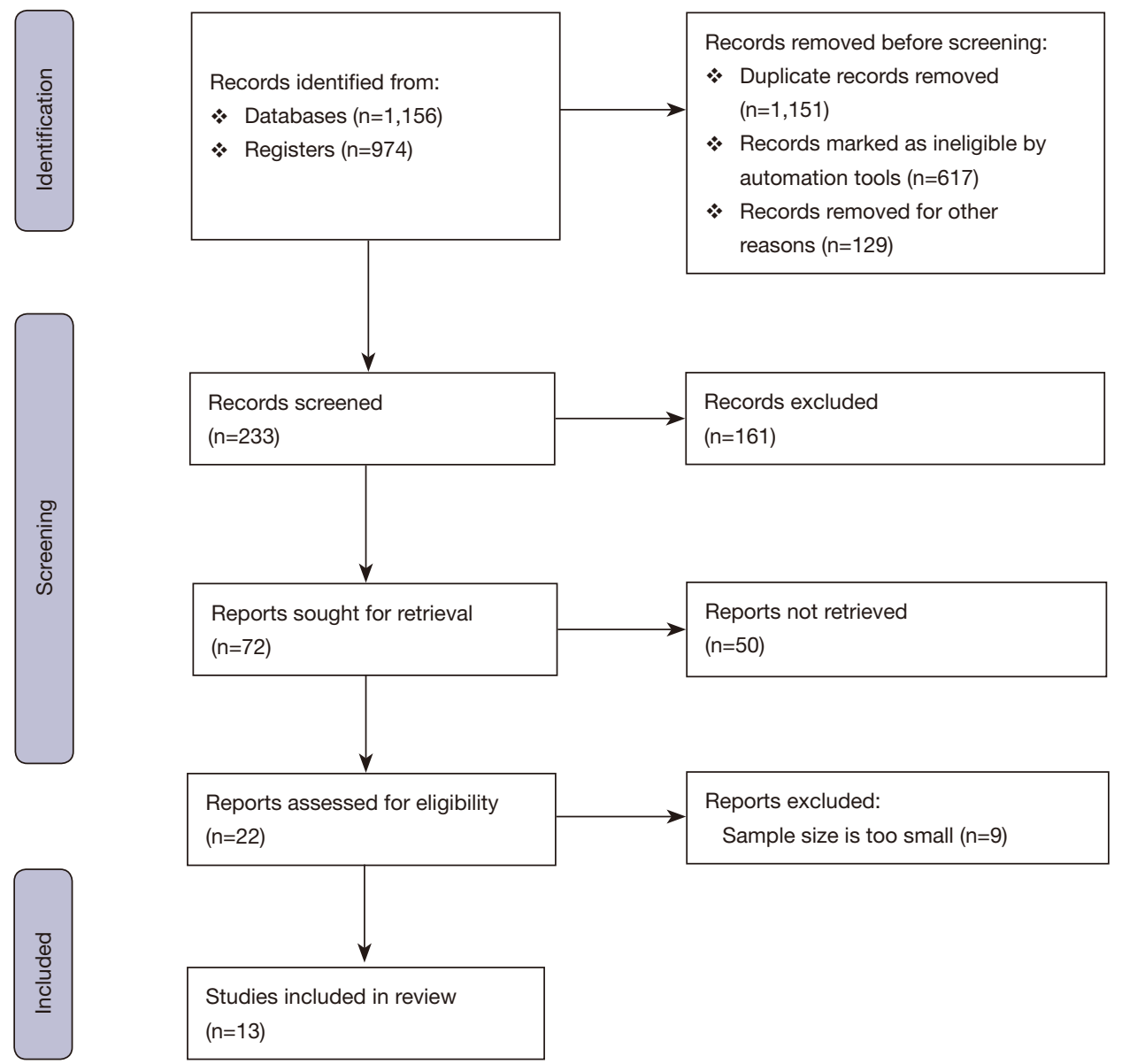

Sample size is too small $(n=9)$

Figure 1 Literature screening process.

seven included articles (Figure 8), there was heterogeneity in neonatal weight between the two groups $\left(\mathrm{I}^{2}=59 \%, \mathrm{P}=0.02\right)$. Using a random effect model analysis, it was found that there was no significant heterogeneity in neonatal weight between the two groups ( $M D=-0.16,95 \% \mathrm{CI}:-0.43$ to 0.12 ; $\mathrm{Z}=1.12, \mathrm{P}=0.26$ ).

\section{Depth of cervix}

According to the statistical analysis of the cervical depth of the subjects in the six included articles (Figure 9), there was significant heterogeneity in the cervical depth between the two groups $\left(\mathrm{I}^{2}=90 \%, \mathrm{P}<0.00001\right)$. A random effect model analysis showed that there was no significant heterogeneity in the cervical depth between the two groups $(M D=0.00$, $95 \%$ CI: -0.20 to $0.21 ; \mathrm{Z}=0.03, \mathrm{P}=0.97$ ).

\section{Elastic modulus of perineal body}

According to the statistical analysis of the elastic modulus of the perineal body of the research objects reported in the three included articles (Figure 10), there was significant heterogeneity between the two groups $\left(\mathrm{I}^{2}=69 \%, \mathrm{P}=0.04\right)$. Using the random effect model analysis, it was found that the elastic modulus of the perineal body of the research group was significantly higher than that of the control group (MD =8.11, 95\% CI: 3.90-12.31; $Z=3.78, P=0.0002)$.

\section{Comparison of SWV in placental border}

Statistical analysis of the SWV at the edge of the placenta of the subjects in the three included papers (Figure 11) showed that there was significant heterogeneity in the SWV 
Table 1 Basic characteristics of included articles

\begin{tabular}{|c|c|c|c|c|c|}
\hline Included studies & Year & Countries & Study design & Research group (n) & Control group (n) \\
\hline Arslan H (23) & 2019 & Turkey & Prospective cohort study & 20 & 20 \\
\hline Castro L (24) & 2020 & Spain & Prospective cohort study & 4 & 23 \\
\hline Gennisson JL (25) & 2011 & France & Retrospective control study & 9 & 11 \\
\hline Jiao Y (27) & 2020 & China & Retrospective control study & 68 & 65 \\
\hline Lai HW (28) & 2020 & China & Prospective cohort study & 36 & 223 \\
\hline Lu J (29) & 2020 & China & Prospective cohort study & 82 & 393 \\
\hline Muller M (30) & 2015 & France & Retrospective control study & 81 & 73 \\
\hline Suthasmalee S (33) & 2019 & Thailand & Prospective cohort study & 10 & 110 \\
\hline Yuksel MA (34) & 2016 & Turkey & Retrospective control study & 33 & 43 \\
\hline
\end{tabular}

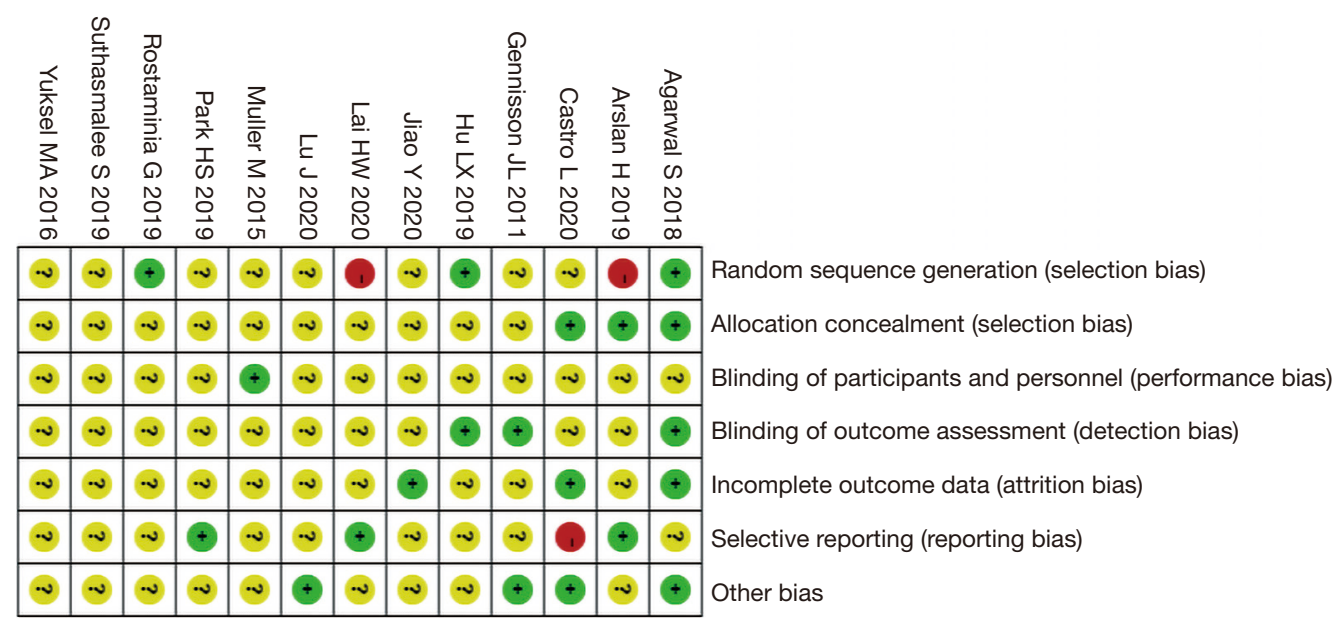

Figure 2 A literature bias risk assessment map of articles included in meta-analysis.

at the edge of the placenta between the two groups $\left(\mathrm{I}^{2}=95 \%\right.$, $\mathrm{P}<0.00001)$. Random effect model analysis showed that there was no significant heterogeneity in the SWV at the edge of the placenta between the two groups $(M D=0.17$, 95\% CI: -0.30 to $0.64 ; \mathrm{Z}=0.71, \mathrm{P}=0.48$ ).

\section{Comparison of SWV in anterior lip}

According to the statistical analysis of the SWV of the anterior lip of the subjects in the three included articles
(Figure 12), there was no significant heterogeneity in the $\mathrm{SWV}$ of the two groups $\left(\mathrm{I}^{2}=0, \mathrm{P}=0.57\right)$. Using FEM analysis, it was found that there was no significant heterogeneity in the SWV of the two groups ( $M D=0.03,95 \%$ CI: -0.24 to $0.30 ; \mathrm{Z}=0.19, \mathrm{P}=0.85$ ).

\section{Comparison of SWV in posterior lip}

According to the statistical analysis of the SWV of the posterior lip of the subjects in the three included articles 


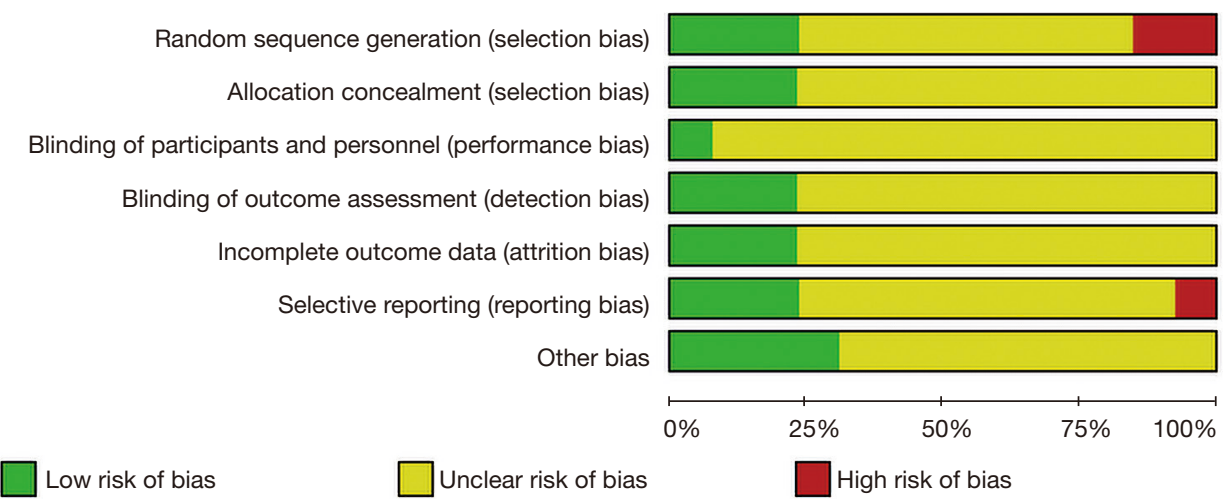

Figure 3 Document bias risk assessment for meta-analysis bar charts.

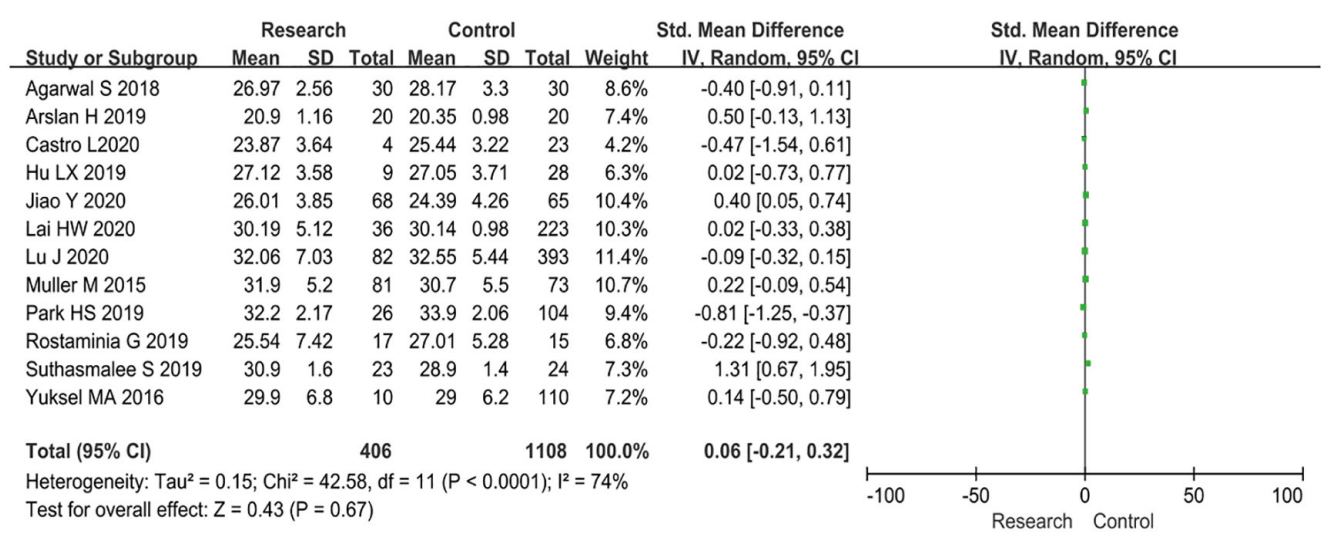

Figure 4 Age comparison between the two groups. SD, standard deviation; CI, confidence interval.

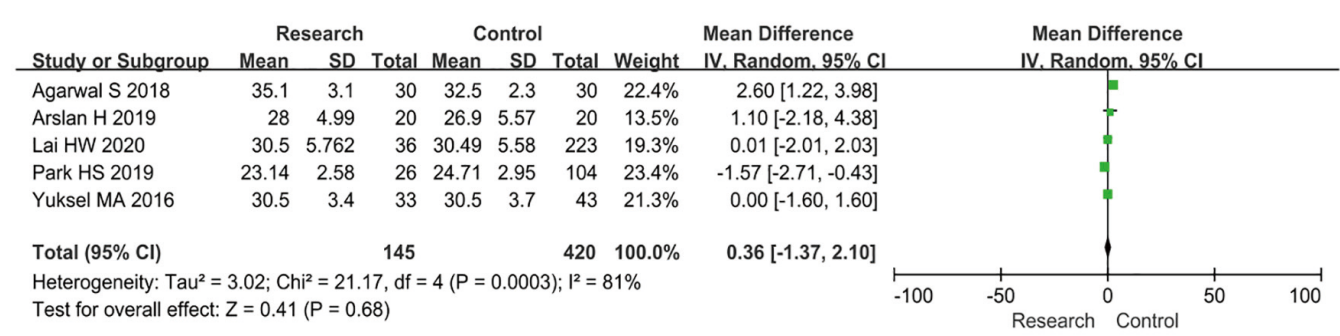

Figure 5 Comparison of fetal ages between the two groups of gray-scale ultrasonography combined with shear wave elastography examination. SD, standard deviation; CI, confidence interval.

(Figure 13), there was no significant heterogeneity in the SWV of the two groups $\left(\mathrm{I}^{2}=0, \mathrm{P}=0.53\right)$. The FEM analysis showed that there was no significant heterogeneity in the SWV of the posterior lip between the two groups (MD $=-0.03,95 \%$ CI: -0.19 to $0.14 ; \mathrm{Z}=0.31, \mathrm{P}=0.76$ ).

\section{Comparison of shear wave elasticity of anterior lip}

According to the statistical analysis of the SWE of the anterior lip of the subjects in the three included articles (Figure 14), there was no significant heterogeneity between the two groups $\left(\mathrm{I}^{2}=0, \mathrm{P}=0.42\right)$. Using FEM analysis, it was 


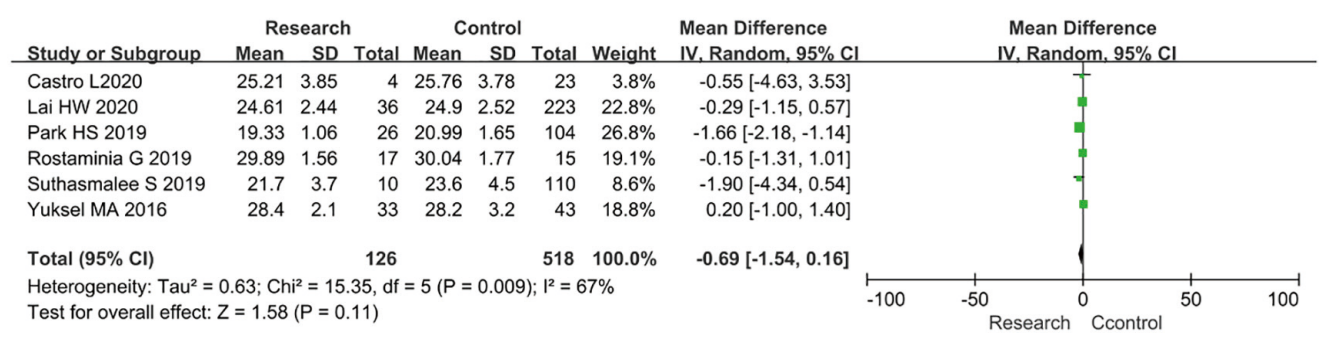

Figure 6 Comparison of body mass index between the two groups before delivery. SD, standard deviation; CI, confidence interval.

\begin{tabular}{|c|c|c|c|c|c|c|c|c|c|c|c|}
\hline Study or Subgroup & \multicolumn{3}{|c|}{ Research } & \multicolumn{2}{|c|}{ Control } & Total & Weight & $\begin{array}{l}\text { Mean Difference } \\
\text { IV. Random. } 95 \% \mathrm{Cl}\end{array}$ & \multicolumn{3}{|c|}{$\begin{array}{c}\text { Mean Difference } \\
\text { IV. Random. } 95 \% \mathrm{Cl}\end{array}$} \\
\hline Agarwal S 2018 & 37.5 & 2 & 30 & 38 & 1.2 & 30 & $17.2 \%$ & $-0.50[-1.33,0.33]$ & & & \\
\hline Gennisson JL 2011 & 39.6 & 1.9 & 9 & 38.4 & 2.2 & 11 & $13.6 \%$ & $1.20[-0.60,3.00]$ & & 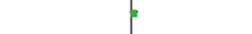 & \\
\hline Lai HW 2020 & 38.82 & 1.69 & 36 & 38.61 & 1.73 & 223 & $17.9 \%$ & $0.21[-0.39,0.81]$ & & & \\
\hline Park HS 2019 & 35.36 & 3.32 & 26 & 38.71 & 1.57 & 104 & $15.5 \%$ & $-3.35[-4.66,-2.04]$ & & - & \\
\hline Suthasmalee S 2019 & 35.7 & 1.2 & 10 & 38.9 & 0.9 & 110 & $17.5 \%$ & $-3.20[-3.96,-2.44]$ & & - & \\
\hline Yuksel MA 2016 & 38.8 & 0.7 & 33 & 38.7 & 1.1 & 43 & $18.3 \%$ & $0.10[-0.31,0.51]$ & & 1 & \\
\hline Total $(95 \% \mathrm{Cl})$ & & & 144 & & & 521 & $100.0 \%$ & $-0.95[-2.22,0.33]$ & & 1 & \\
\hline $\begin{array}{l}\text { Heterogeneity: } \mathrm{Tau}^{2}= \\
\text { Test for overall effect: }\end{array}$ & $\begin{array}{l}2.26 ; \mathrm{Chi} \\
\mathrm{z}=1.46\end{array}$ & $\begin{array}{l}2=83 . \\
(P=0 .\end{array}$ & $\begin{array}{l}55, \mathrm{df}= \\
14)\end{array}$ & $=5(\mathrm{P}$ & 0.000 & 01); $\left.\right|^{2}=$ & $=94 \%$ & & -100 & $\begin{array}{lll}-50 & 0 & 50\end{array}$ & 100 \\
\hline
\end{tabular}

Figure 7 Comparison of fetal gestational age at delivery. SD, standard deviation; CI, confidence interval.

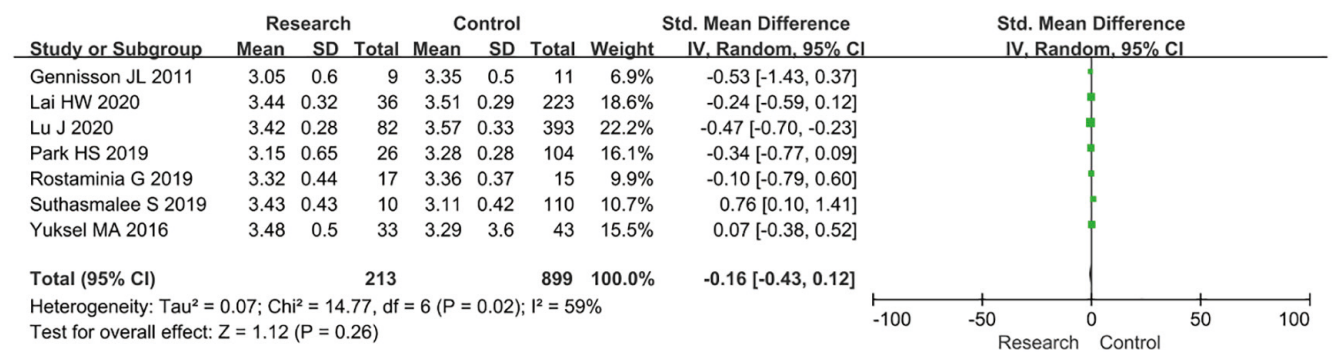

Figure 8 Comparison of newborn weight. SD, standard deviation; CI, confidence interval.

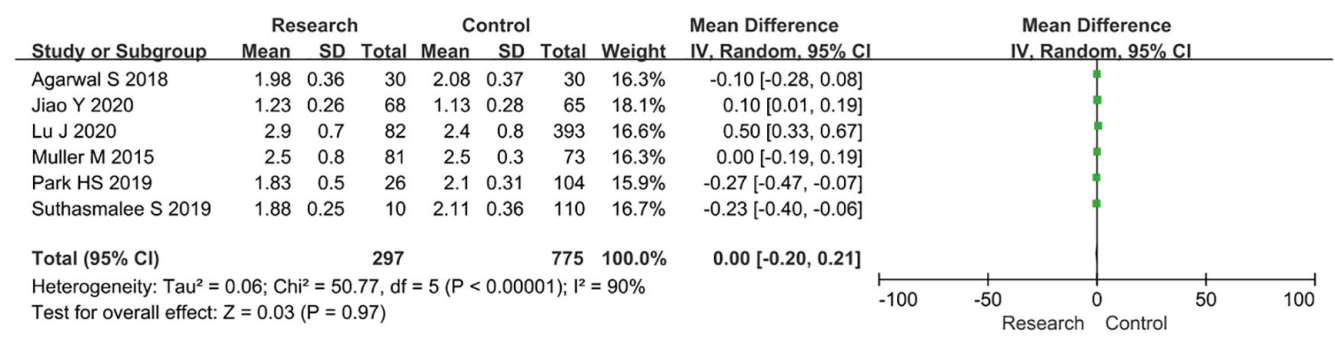

Figure 9 Comparison of cervical depth. SD, standard deviation; CI, confidence interval. 


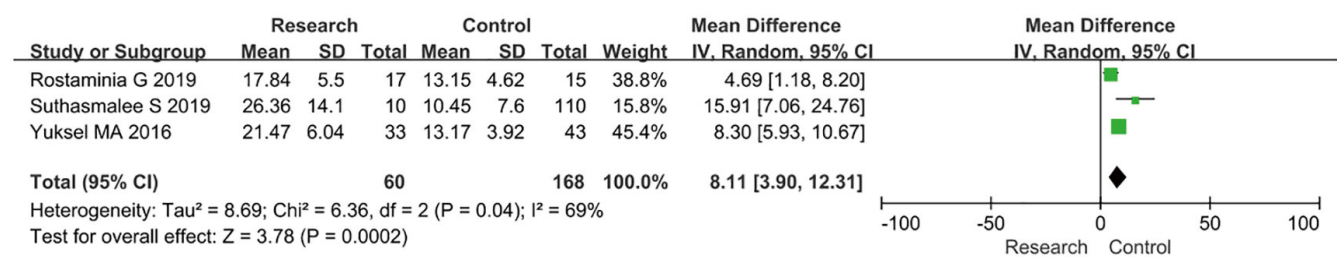

Figure 10 Comparison of elastic modulus of perineal body. SD, standard deviation; CI, confidence interval.

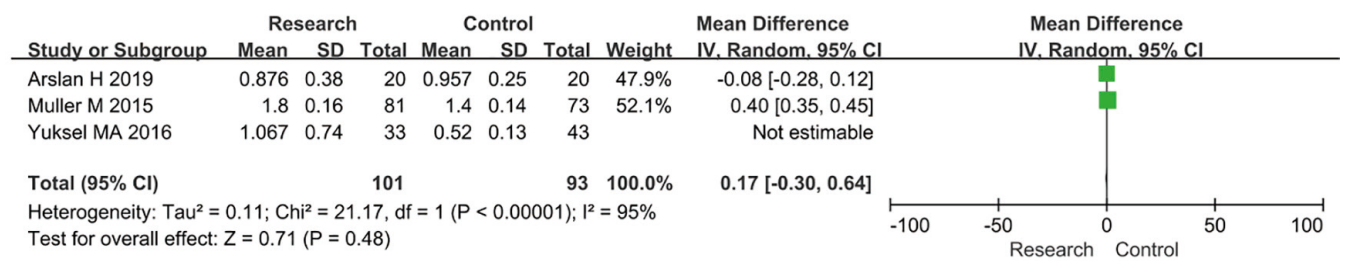

Figure 11 Comparison of shear wave velocity at the edge of placenta. SD, standard deviation; CI, confidence interval.

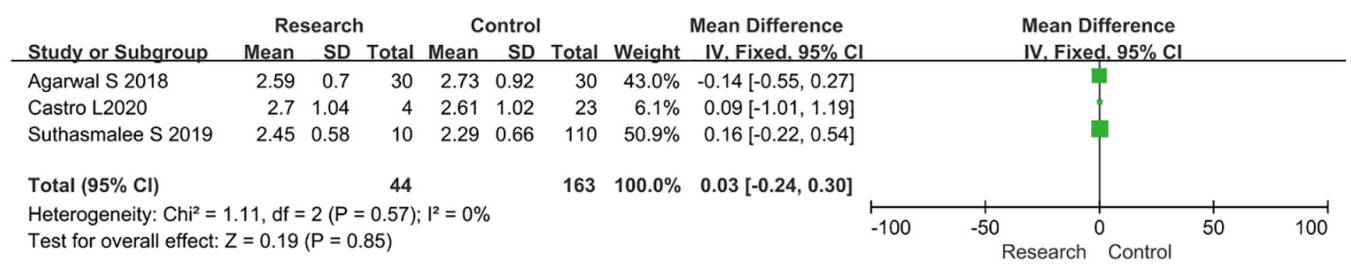

Figure 12 Comparison of shear wave velocity of anterior lip. SD, standard deviation; CI, confidence interval.

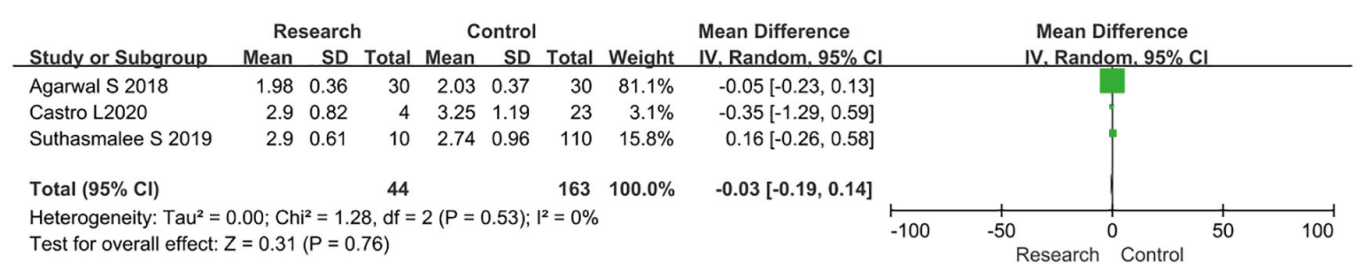

Figure 13 Comparison of shear wave velocity of posterior lip. SD, standard deviation; CI, confidence interval.

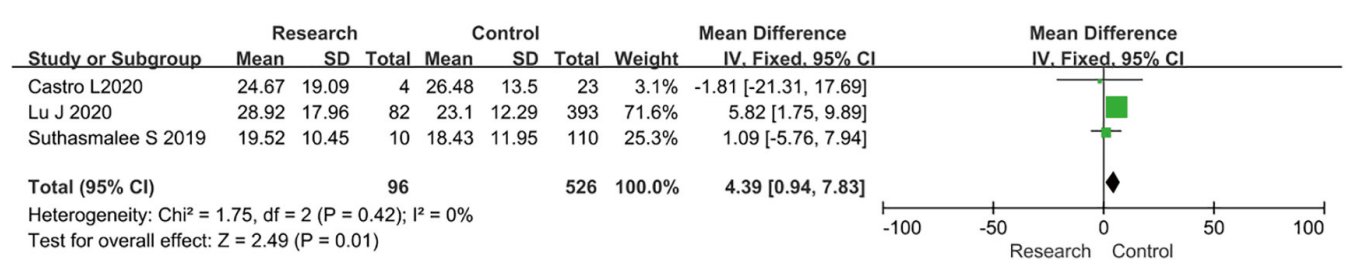

Figure 14 Comparison of shear wave elasticity of anterior lip. SD, standard deviation; CI, confidence interval. 


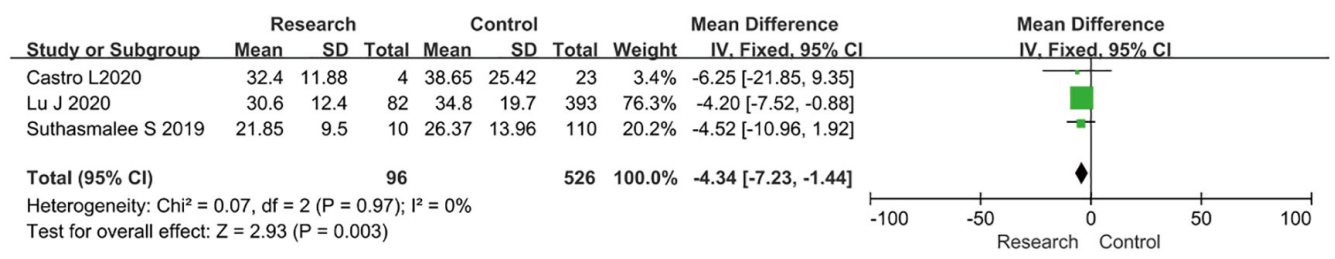

Figure 15 Comparison of shear wave elasticity of posterior lip. SD, standard deviation; CI, confidence interval.

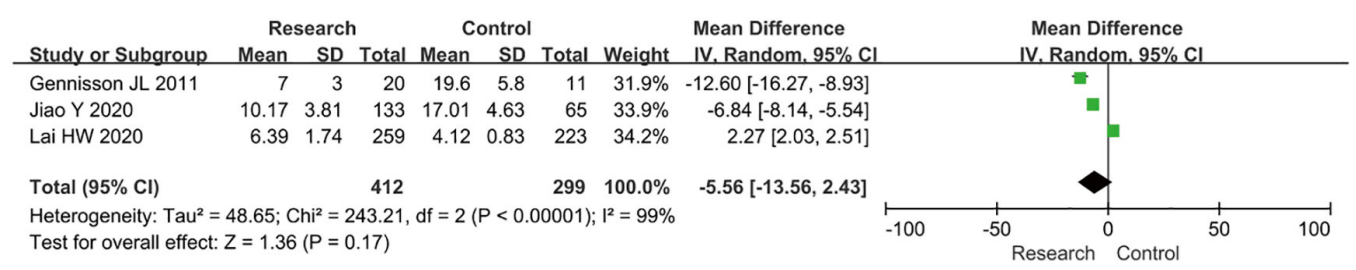

Figure 16 Comparison of Young's modulus values. SD, standard deviation; CI, confidence interval.

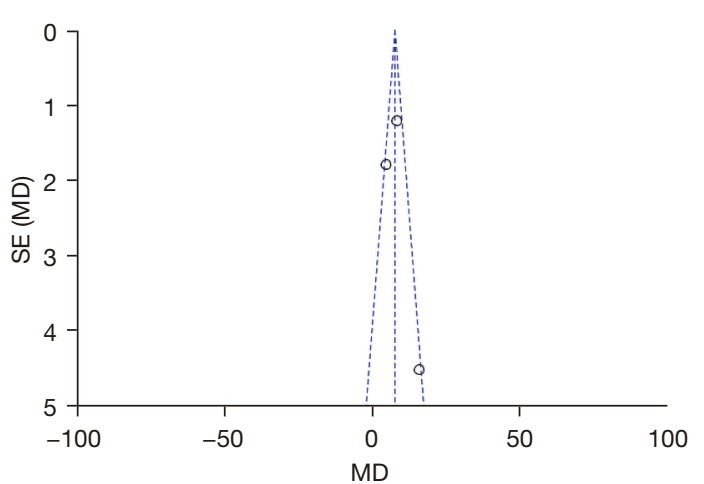

Figure 17 Evaluation of funnel plot for publication bias of perineal body elasticity modulus. SE, standard error; MD, mean difference.

found that the SWE of the anterior lip of the study group was significantly higher than that of the control group (MD $=4.39,95 \%$ CI: $0.94-7.83 ; \mathrm{Z}=2.49, \mathrm{P}=0.01$ ).

\section{Comparison of shear wave elasticity of posterior lip}

According to the statistical analysis of the posterior lip SWE of the subjects in the three included articles (Figure 15), there was no significant heterogeneity between the two groups $\left(\mathrm{I}^{2}=0, \mathrm{P}=0.97\right)$. The FEM analysis showed that the posterior lip SWE of the study group was significantly lower than that of the control group (MD $=-4.34,95 \%$ CI: -7.23 to $-1.44 ; \mathrm{Z}=2.93, \mathrm{P}=0.003$ ).

\section{Comparison of Young's modulus}

A statistical analysis was conducted on the comparison of Young's modulus values of the subjects in the three included articles (Figure 16). There was significant heterogeneity in the comparison of Young's modulus values between the two groups $\left(\mathrm{I}^{2}=99 \%, \mathrm{P}<0.00001\right)$. Random effect model analysis showed that there was no significant heterogeneity in the comparison of Young's modulus values between the two groups ( $\mathrm{MD}=-5.56,95 \% \mathrm{CI}:-13.56$ to $2.43 ; \mathrm{Z}=1.36$, $\mathrm{P}=0.17)$.

\section{Publication bias analysis results}

The funnel chart of publication bias evaluation based on the elastic modulus of perineal body, SWE of anterior lip, and SWE of posterior lip is shown in Figures 17-19. All the studies are distributed on both sides of the funnel and are basically symmetrical, indicating that the possibility of publication bias was low. The funnel plot of publication bias of other indicators demonstrated that the possibility of publication bias was low.

\section{Discussion}

The methods currently used for the diagnosis of pregnancy and childbirth of primiparas mainly include: $\mathrm{X}$-ray pelvic organography, MRI, and ultrasound. X-ray pelvic organ 


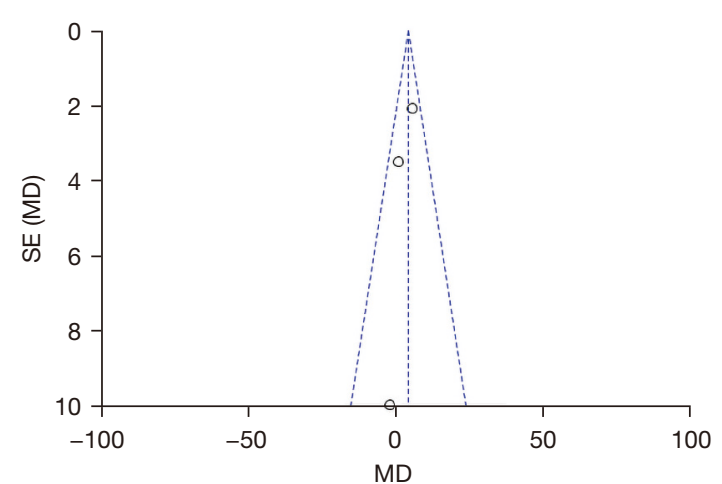

Figure 18 Evaluation of funnel plot for publication bias of anterior lip shear wave elasticity. SE, standard error; MD, mean difference.

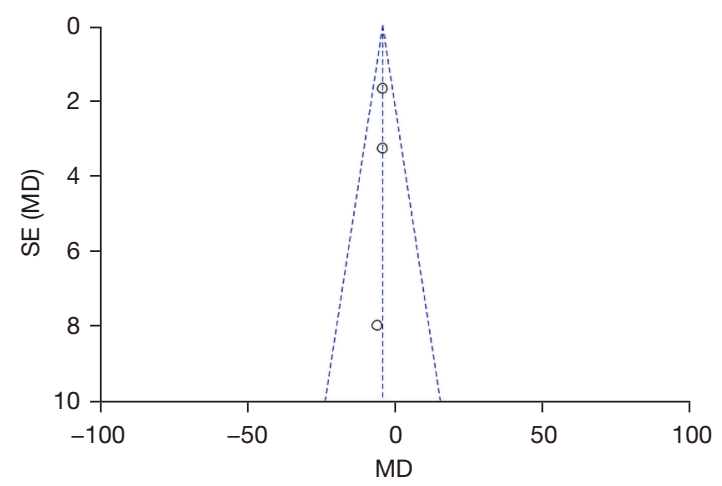

Figure 19 Evaluation of funnel plot for publication bias of posterior lip shear wave elasticity. SE, standard error; MD, mean difference.

angiography can evaluate the function of pelvic organs according to the speed and extent of the discharge of the contrast agent. However, the examination process is cumbersome and takes a long time, and the morphological and functional status of the rectal and anal canal is poor in its surrounding soft tissues (35). MRI relies on its own advantages of high resolution of soft tissues, capable of multi-parameter imaging and no ionizing radiation, comprehensively assessing the structure and function of the pelvic floor, and has become the imaging gold standard for evaluating the structure and function of the pelvic floor. However, the cost of MRI examination is high, the examination time is long, and the pelvic floor can't be assessed (36). Ultrasound has attracted more and more attention in the diagnosis of pelvic floor dysfunction diseases because of its unique advantages such as simple operation, real-time and fast, economical non-invasive, repeatable examination, and high resolution of soft tissues (37). Twodimensional (2D) ultrasound can dynamically observe and evaluate the position and activity of the pelvic floor organs in the early postpartum period of the primipara after vaginal delivery. Early postpartum pelvic floor tissues of primiparas undergo vaginal delivery are weak, defective, or have a certain degree of dysfunction, especially in the former and middle pelvic organs (38). However, 2D ultrasound can only detect on a single plane, and can't observe the complete morphological structure of the pelvic floor and the spatial relationship between the levator ani muscle and surrounding tissues (39). Although 2D and threedimensional (3D) ultrasound and tomographic ultrasound imaging (TUI) can indirectly reflect the elasticity of the levator ani muscle by measuring the thickness and length of the levator ani muscle, the inner diameter and area of the levator ani muscle hiatus, they can't quantitatively evaluate the elasticity of the levator ani muscle (40).

SWE uses ultrasound probes to emit sound pulses to excite the tissue, focus at different depths of the tissue to generate a transverse shear wave that is much lower than the speed of sound, adopts ultra-high-speed imaging technology to obtain high-time resolution images of the shear wave, and applies the quantitative analysis system to directly obtain the Young's modulus value of the region of interest. The greater the hardness of the organization, the faster the propagation speed of the shear wave in the organization, and the greater the Young's modulus value, then the area will be displayed in red on the elastic diagram; otherwise, the smaller the Young's modulus value, the area will be in It is displayed in blue on the elastic graph. The application of SWE technology in breast, thyroid, liver, and other tissues is quite mature (41). Gray-scale ultrasound combined with SWE is a new imaging technology of tissue mechanics characteristics. It can distinguish the hardness of different tissues by image elastic value (42). It can not only display the relative elasticity of the tissue in real time, but also reflect the absolute value of different elastic modulus and then quantitatively assess the hardness of the tissue (43). Shear wave elasticity can continuously focus the ultrahigh speed pulse wave through the probe to generate shear waves of different intensities in different tissues and finally obtain the tissue elastic graph and elastic values of tissues (44). It has the advantages of fast image acquisition, small interference factors, good reproducibility, repeatability, and easy operation (45). During pregnancy, the pressure of the basin increases due to the increase of fetal weight and the uterus, resulting in changes in 
the anatomical structures of ligaments and fascia in the basin (46). Therefore, we can evaluate the tissue changes of primiparas after pregnancy and delivery using high-order ultrasound combined with SWE.

This study included 13 clinical studies on gray-scale ultrasound combined with SWE in the diagnosis of primipara pregnancy delivery. By comparing the clinical indicators of primiparas and non-primiparas as well as the changes of the related indicators of the echocardiography combined with SWE scanning images, the change trend of the relevant parameters of primiparas after pregnancy and delivery was analyzed. The results showed that: compared with the control group, there were no significant differences in the age of primiparas, gestational age at the time of grayscale ultrasound combined with SWE examination, BMI before delivery, gestational age at delivery, neonatal weight, cervical depth, SWV of placenta margin, SWV of anterior lip, and SWV of lip and Young's modulus in the study group. The elastic modulus of the perineal body and the SWE of the anterior lip in the study group were significantly higher than those in the control group. The SWE of the posterior lip of the study group was significantly lower than that of the control group. It showed that the elastic modulus of the perineal body, the SWE of the anterior lip and the SWE of the posterior lip were significantly changed for primipara after pregnancy and delivery. The results of Spiliopoulos et al. pointed out that the average Young's modulus of the perineum in the non-fertile group was greater than that of the cesarean section, and the average Young's modulus of the perineum in the cesarean section was greater than that of the vaginal delivery group $(\mathrm{P}<0.05)$, suggesting that the damage of the perineal body is more obvious in the vaginal delivery group (47). In cesarean section, due to the influence of pregnancy uterus weight and hormone levels, the muscle strength of the perineal body is impaired and the elasticity value is reduced (48).

\section{Conclusions}

In this study, a meta-analysis was used to analyze the diagnostic value of gray-scale ultrasound combined with SWE in the delivery of primiparas. By comparing the changes of clinical parameters, gray-scale ultrasound and SWE detection parameters, we discussed the diagnostic value of gray-scale ultrasound combined with SWE for the delivery of primiparas. The results showed that there was no significant difference in clinical index, placental marginal SWV, lip SWV, lip SWV and Young's modulus between primipara and the control group. The elasticity modulus of the perineal body, the SWE of the front lip, and the SWE of the posterior lip were significantly changed. However, in this study, the number of cases in the control group was significantly more than that in the observation group in the relevant studies on gray-scale ultrasound combined with SWE in the evaluation of pregnancy and childbirth. Moreover, there were few descriptions of grayscale ultrasound combined with SWE indicators in the included literature, and there may be a certain degree of bias for indicators with no obvious heterogeneity, and a lot of clinical verification was needed for further analysis. However, this study can still provide some reference values for the diagnosis of primipara pregnancies.

\section{Acknowledgments}

Funding: None.

\section{Footnote}

Reporting Checklist: The authors have completed the PRISMA reporting checklist. Available at https://dx.doi. org/10.21037/apm-21-2672

Conflicts of Interest: All authors have completed the ICMJE uniform disclosure form (available at https://dx.doi. org/10.21037/apm-21-2672). The authors have no conflicts of interest to declare.

Ethical Statement: The authors are accountable for all aspects of the work in ensuring that questions related to the accuracy or integrity of any part of the work are appropriately investigated and resolved.

Open Access Statement: This is an Open Access article distributed in accordance with the Creative Commons Attribution-NonCommercial-NoDerivs 4.0 International License (CC BY-NC-ND 4.0), which permits the noncommercial replication and distribution of the article with the strict proviso that no changes or edits are made and the original work is properly cited (including links to both the formal publication through the relevant DOI and the license). See: https://creativecommons.org/licenses/by-nc-nd/4.0/.

\section{References}

1. Betschart C, Singer A, Scheiner D. Female pelvic 
floor: anatomy and normal function. Ther Umsch 2019;73:529-34.

2. Louis-Charles K, Biggie K, Wolfinbarger A, et al. Pelvic Floor Dysfunction in the Female Athlete. Curr Sports Med Rep 2019;18:49-52.

3. Berghmans B. Physiotherapy for pelvic pain and female sexual dysfunction: an untapped resource. Int Urogynecol J 2018;29:631-8.

4. Mateus-Vasconcelos ECL, Ribeiro AM, Antônio FI, et al. Physiotherapy methods to facilitate pelvic floor muscle contraction: A systematic review. Physiother Theory Pract 2018;34:420-32.

5. Navarro Brazález B, Torres Lacomba M, de la Villa P, et al. The evaluation of pelvic floor muscle strength in women with pelvic floor dysfunction: A reliability and correlation study. Neurourol Urodyn 2018;37:269-77.

6. Angelo PH, Varella LRD, de Oliveira MCE, et al. A manometry classification to assess pelvic floor muscle function in women. PLoS One 2017;12:e0187045.

7. Fujisaki A, Shigeta $M$, Shimoinaba $M$, et al. Influence of adequate pelvic floor muscle contraction on the movement of the coccyx during pelvic floor muscle training. J Phys Ther Sci 2018;30:544-8.

8. Jamard E, Blouet M, Thubert T, et al. Utility of 2D-ultrasound in pelvic floor muscle contraction and bladder neck mobility assessment in women with urinary incontinence. J Gynecol Obstet Hum Reprod 2020;49:101629.

9. Gaulrapp H. Clinical examination, imaging and therapy of Osgood-Schlatter's disease. Orthopade 2016;45:219-25.

10. Nyhus MØ, Oversand SH, Salvesen Ø, et al. Ultrasound assessment of pelvic floor muscle contraction: reliability and development of an ultrasound-based contraction scale. Ultrasound Obstet Gynecol 2020;55:125-31.

11. Sigrist RMS, Liau J, Kaffas AE, et al. Ultrasound Elastography: Review of Techniques and Clinical Applications. Theranostics 2017;7:1303-29.

12. Prado-Costa R, Rebelo J, Monteiro-Barroso J, et al. Ultrasound elastography: compression elastography and shear-wave elastography in the assessment of tendon injury. Insights Imaging 2018;9:791-814.

13. Gatz M, Bejder L, Quack V, et al. Shear Wave Elastography (SWE) for the Evaluation of Patients with Plantar Fasciitis. Acad Radiol 2020;27:363-70.

14. Furlan A, Tublin ME, Yu L, et al. Comparison of 2D Shear Wave Elastography, Transient Elastography, and MR Elastography for the Diagnosis of Fibrosis in Patients With Nonalcoholic Fatty Liver Disease. AJR Am J
Roentgenol 2020;214:W20-6.

15. Arioz Habibi H, Alici Davutoglu E, Kandemirli SG, et al. In vivo assessment of placental elasticity in intrauterine growth restriction by shear-wave elastography. Eur J Radiol 2017;97:16-20.

16. Yang H, Carrascal CA, Xie H, et al. 2-D Ultrasound Shear Wave Elastography With Multi-Sphere-Source External Mechanical Vibration: Preliminary Phantom Results. Ultrasound Med Biol 2020;46:2505-19.

17. Aljuraifani R, Stafford RE, Hug F, et al. Female striated urogenital sphincter contraction measured by shear wave elastography during pelvic floor muscle activation: Proof of concept and validation. Neurourol Urodyn 2018;37:206-12.

18. Erdoğan H, Durmaz MS, Özbakır B, et al. Experience of using shear wave elastography in evaluation of testicular stiffness in cases of male infertility. J Ultrasound 2020;23:529-34.

19. Tang JH, Zhong C, Wen W, et al. Quantifying Levator Ani Muscle Elasticity Under Normal and Prolapse Conditions by Shear Wave Elastography: A Preliminary Study. J Ultrasound Med 2020;39:1379-88.

20. Tanridan Okcu N, Vuruskan E, Gorgulu FF. Use of Shear Wave Elastography to Evaluate Stress Urinary Incontinence in Women. J Coll Physicians Surg Pak 2021;31:1196-201.

21. Gachon B, Nordez A, Pierre F, et al. In vivo assessment of the levator ani muscles using shear wave elastography: a feasibility study in women. Int Urogynecol J 2019;30:1179-86.

22. Agarwal S, Agarwal A, Joon P, et al. Fetal adrenal gland biometry and cervical elastography as predictors of preterm birth: A comparative study. Ultrasound 2018;26:54-62.

23. Arslan H, Tolunay HE, Cim N, et al. Shear-wave elastography - virtual touch tissue quantification of fetal placentas with a single umbilical artery. J Matern Fetal Neonatal Med 2019;32:2481-5.

24. Castro L, García-Mejido JA, Arroyo E, et al. Influence of epidemiological characteristics (age, parity and other factors) in the assessment of healthy uterine cervical stiffness evaluated through shear wave elastography as a prior step to its use in uterine cervical pathology. Arch Gynecol Obstet 2020;302:753-62.

25. Gennisson JL, Muller M., Ami O, et al. Shear wave elastography in obstetrics: quantification of cervix elasticity and uterine contraction. 2011 IEEE International Ultrasonics Symposium, 18-21 Oct. 2011; Orlando, FL, USA. IEEE, 2011:2094-7. 
26. Hu L, Li L, Wang H, et al. Quantitative evaluation of female pelvic floor muscle biomechanics using ultrasound elastography. IEEE Access 2019;7:60940-6.

27. Jiao Y, Xue N, Zou C, et al. Assessment of early damage of endometrium after artificial abortion by shear wave elastography. Insights Imaging 2020;11:28.

28. Lai HW, Lyv GR, Wei YT, et al. The diagnostic value of two-dimensional shear wave elastography in gestational diabetes mellitus. Placenta 2020;101:147-53.

29. Lu J, Cheng YKY, Ho SYS, et al. The predictive value of cervical shear wave elastography in the outcome of labor induction. Acta Obstet Gynecol Scand 2020;99:59-68.

30. Muller M, Aït-Belkacem D, Hessabi M, et al. Assessment of the Cervix in Pregnant Women Using Shear Wave Elastography: A Feasibility Study. Ultrasound Med Biol 2015;41:2789-97.

31. Park HS, Kwon H, Kwak DW, et al. Addition of Cervical Elastography May Increase Preterm Delivery Prediction Performance in Pregnant Women with Short Cervix: a Prospective Study. J Korean Med Sci 2019;34:e68.

32. Rostaminia G, Awad C, Chang C, et al. Shear Wave Elastography to Assess Perineal Body Stiffness During Labor. Female Pelvic Med Reconstr Surg 2019;25:443-7.

33. Suthasmalee S, Moungmaithong S. Cervical shear wave elastography as a predictor of preterm delivery during 18-24weeks of pregnancy. J Obstet Gynaecol Res 2019;45:2158-68.

34. Yuksel MA, Kilic F, Kayadibi Y, et al. Shear wave elastography of the placenta in patients with gestational diabetes mellitus. J Obstet Gynaecol 2016;36:585-8.

35. Snaith B, Field L, Lewis EF, et al. Variation in pelvic radiography practice: Why can we not standardise image acquisition techniques? Radiography (Lond) 2019;25:374-7.

36. Lakhoo J, Khatri G, Elsayed RF, et al. MRI of the Male Pelvic Floor. Radiographics 2019;39:2003-22.

37. Piessens S, Edwards A. Sonographic Evaluation for Endometriosis in Routine Pelvic Ultrasound. J Minim Invasive Gynecol 2020;27:265-6.

38. McKee D, Young S, Magtibay P, et al. Intraoperative Deep Pelvic Ultrasound for Detection of Ileocecal Endometriosis. J Minim Invasive Gynecol 2021;28:1125-7.

39. Dias TD, Palihawadana TS, Patabendige $M$, et al. Ultrasound parameters of pelvic organs and their age-related changes in a cohort of asymptomatic postmenopausal women: A community-based study. Post Reprod Health 2020;26:147-54.
40. Mandava A, Koppula V, Kandati M, et al. Ultrasound in the Diagnosis of Malignant Pelvic Fistulas: Sonographic Findings in Correlation with Computed Tomography Imaging. Ultrasound Med Biol 2020;46:3460-7.

41. Gachon B, Fritel X, Pierre F, et al. In vivo assessment of the elastic properties of women's pelvic floor during pregnancy using shear wave elastography: design and protocol of the ELASTOPELV study. BMC Musculoskelet Disord 2020;21:305.

42. Stafford RE, Aljuraifani R, Hug F, et al. Application of shear-wave elastography to estimate the stiffness of the male striated urethral sphincter during voluntary contractions. BJU Int 2017;119:619-25.

43. Hu X, Liu Y, Qian L. Diagnostic potential of real-time elastography (RTE) and shear wave elastography (SWE) to differentiate benign and malignant thyroid nodules: A systematic review and meta-analysis. Medicine (Baltimore) 2017;96:e8282.

44. Huang C, Song P, Mellema DC, et al. Three-dimensional shear wave elastography on conventional ultrasound scanners with external vibration. Phys Med Biol 2020;65:215009.

45. O'Hara S, Zelesco M, Rocke K, et al. Reliability Indicators for 2-Dimensional Shear Wave Elastography. J Ultrasound Med 2019;38:3065-71.

46. Lee DH, Lee JY, Bae JS, et al. Shear-Wave Dispersion Slope from US Shear-Wave Elastography: Detection of Allograft Damage after Liver Transplantation. Radiology 2019;293:327-33.

47. Spiliopoulos M, Kuo CY, Eranki A, et al. Characterizing placental stiffness using ultrasound shear-wave elastography in healthy and preeclamptic pregnancies. Arch Gynecol Obstet 2020;302:1103-12.

48. Peralta L, Mourier E, Richard C, et al. In Vivo Evaluation of Cervical Stiffness Evolution during Induced Ripening Using Shear Wave Elastography, Histology and 2 Photon Excitation Microscopy: Insight from an Animal Model. PLoS One 2015;10:e133377.

(English Language Editor: B. Meiser)

Cite this article as: Qu Y, Sun H, Chen J, Bai J, Liu Y, You Y. Systematic review and meta-analysis: gray-scale ultrasound and shear wave elastography in the diagnosis of primipara pregnancy and delivery. Ann Palliat Med 2021;10(11):11664-11677. doi: $10.21037 / \mathrm{apm}-21-2672$ 